\title{
Fasting and Nonfasting Triglycerides in Cardiovascular and Other Diseases
}

\author{
J. PIŤHA ${ }^{1}$, J. KOVÁŘ ${ }^{1}$, T. BLAHOVÁ ${ }^{1}$ \\ ${ }^{1}$ Laboratory for Atherosclerosis Research, Center for Experimental Medicine, Institute for Clinical \\ and Experimental Medicine, Prague, Czech Republic
}

Received September 21, 2015

Accepted October 5, 2015

\section{Summary}

Moderately elevated plasma/serum triglycerides $(2-10 \mathrm{mmol} / \mathrm{l})$ signalize increased risk for cardiovascular disease or presence of non-alcoholic steatohepatitis. Extremely elevated triglycerides (more than $10 \mathrm{mmol} / \mathrm{l}$ ) signalize increased risk for pancreatitis and lipemia retinalis. The concentration of triglycerides is regulated by many genetic and nongenetic factors. Extremely elevated triglycerides not provoked by nutritional factors, especially inappropriate alcohol intake are more likely to have a monogenic cause. On the contrary, mildly to moderately elevated triglycerides are often caused by polygenic disorders; these could be also associated with central obesity, insulin resistance, and diabetes mellitus. Concentration of triglycerides is also closely interconnected with presence of atherogenic remnant lipoproteins, impaired reverse cholesterol transport and more atherogenic small LDL particles. In general, there is tight association between triglycerides and many other metabolic factors including intermediate products of lipoprotein metabolism which are frequently atherogenic. Therefore, reliable evaluation of the independent role of triglycerides especially in atherosclerosis and cardiovascular disease is difficult. In individual cases values of HDL cholesterol, non-HDL cholesterol (total minus HDL cholesterol), non-HDL/nonLDL cholesterol (total minus HDL minus LDL cholesterol, especially in nonfasting status), atherogenic index of plasma and/or apolipoprotein B could help in decisions regarding aggressiveness of treatment.

\section{Key words}

Fasting triglycerides - Nonfasting triglycerides - Cardiovascular disease $\bullet$ Lipoproteins

\section{Corresponding author}

J. Pit'ha, Institute for Clinical and Experimental Medicine, Vídeňská 1958/9, 14021 Prague, Czech Republic. E-mail: japi@ikem.cz

\section{Introduction}

As hunter and a gatherers humans developed several mechanisms for energy storage and expenditure. One of the key players in these processes are triglycerides. Their storage and circulation in blood is kept under control by several enzymes, which are regulated by many genes and they reflect the nutritional needs of organism including fasting and nonfasting status (White 2010, Havel 1994). In addition, triglycerides are closely associated with many other lipid factors. They are positively associated with atherogenic LDL cholesterol, presence of small LDL particles, remnant lipoproteins, apolipoprotein C-III (Apo C-III) and negatively with atheroprotective HDL cholesterol and apolipoprotein C-II (Apo C-II). This implicates that reliable assessment of the real and independent role of circulating triglycerides in the process of atherosclerosis and other diseases in epidemiological and clinical studies is difficult and that robustness of their association with cardiovascular disease depends more on the extent of statistical standardization for other risk and lipid factors than on their real biological role. Epidemiological evidence and evidence from clinical trials must be therefore also supported by some physiological evidence. This review is focused on the role of triglycerides mainly in atherosclerosis and cardiovascular disease and presents 
data from epidemiological and physiological studies and offers some implications for clinical practice. The impact of alcohol and particularly the treatment of hypertriglyceridemia are in detail discussed elsewhere in this supplement (Kovar and Zemankova 2015, Vrablik and Ceska 2015).

\section{Epidemiology and definitions}

In several prospective population-based studies triglycerides for a long time has been found to be significant and independent risk factor for cardiovascular disease with recently renewed interest (Austin 1999, Bansal et al. 2007, Libby 2015, Nordestgaard et al. 2007, Nordestgaard and Varbo 2014, Tirosh et al. 2007).
According to already classic metaanalysis of population based prospective studies, this effect was rather modest in men (response rate per $1 \mathrm{mmol} / 1$ - increase 1.14), but stronger in women (response rate per $1 \mathrm{mmol} / \mathrm{l}$ - increase 1.37) (Hokanson and Austin 1996). In more recent study in women, the strongest effect was observed when nonfasting levels of triglycerides were analyzed (Bansal et al. 2007). Similar findings were found in nonEuropean - Asian and Pacific population (Patel et al. 2004). Most patients manifesting cardiovascular disease have elevated triglycerides accompanied by low HDL cholesterol. This pattern is also most frequently found in patients with peripheral artery disease (Valdivielso et al. 2014a).

Table 1. Definition of hypertriglyceridemia (modified Hegele et al. 2014).

\begin{tabular}{lll}
\hline & Value of triglycerides & \multicolumn{1}{c}{ Risk factor for } \\
\hline $\begin{array}{l}\text { Normal values } \\
\text { Mild-to-moderate } \\
\text { hypertriglyceridemia }\end{array}$ & Less than $1.7 \mathrm{mmol} / 1$ & - \\
Severe hypertriglyceridemia & $1.7-10.0 \mathrm{mmol} / 1$ & Cardiovascular disease \\
& & Non-alcoholic steatohepatitis \\
& More than $10.0 \mathrm{mmol} / 1$ & Pancreatitis \\
\end{tabular}

Hypertriglyceridemia is accordingly to recent recommendations categorized as mild, moderate and extreme (Table 1) (Hegele et al. 2014). Mild to moderate values are most often associated with cardiovascular events and non-alcoholic steatohepatitis while extremely elevated values are most often associated with pancreatitis and lipemia retinalis. On the contrary, low levels especially of nonfasting triglycerides associated with relatively common mutations in lipoprotein lipase (LPL) have positive effect on mortality as found in recent work, in which stepwise reduced risk of mortality by decreasing concentrations of nonfasting plasma triglycerides was detected. In this study age and sex adjusted hazard ratios were 0.84 (95\% CI 0.73-0.96) for 2.00-2.99 mmol/1, 0.67 (95\% CI 0.60-0.76) for 1.00-1.99 $\mathrm{mmol} / \mathrm{l}$, and 0.51 (95\% CI 0.44-0.58) for individuals with nonfasting triglycerides less than $1.00 \mathrm{mmol} / \mathrm{l}$. Similar results were found using multivariably adjusted hazard ratios (Thomsen et al. 2014). This work also confirmed that genetic studies could be in general free from confounding and that they might offer reliable results. Another evidence supporting this finding comes from study focused on morphological signs of atherosclerosis and which proved, that lifelong low triglycerides resulting from genetic polymorphisms are associated with a decreased burden of atherosclerosis expressed as coronary artery calcification (Polin et al. 2008). This study using a genome-wide association approach found that he heterozygous carriers (population of Lancaster Amish) of a null mutation in the gene encoding Apo C-III, which inhibits triglyceride hydrolysis express half the amount of Apo C-III present in noncarriers. Mutation carriers had lower fasting and postprandial serum triglycerides, higher levels of HDLcholesterol and lower levels of LDL-cholesterol. In addition, subclinical atherosclerosis, as measured by coronary artery calcification, was less common in carriers than noncarriers. This suggests that lifelong deficiency of Apo C-III has a cardioprotective effect. On the other hand in prospective observational study of Israeli soldier men increase of triglycerides during 5 years was significantly associated with cardiovascular events (Tirosh et al. 2007). In this study association between changes over time in fasting triglyceride levels and coronary heart 
disease risk was studied. Follow-up was more than 5.5 years after two measurements of fasting triglycerides 5 years apart. In approximately 14,000 healthy, untreated and young men with triglyceride levels less than $3.39 \mathrm{mmol} / \mathrm{l}$ the multivariate model adjusted for age, family history, fasting glucose, high-density lipoprotein cholesterol, blood pressure, body mass index, and changes between time 1 and time 2 in body mass index, physical activity, smoking status, and habit of eating breakfast revealed that triglyceride levels according to low, intermediate, and high tertiles (as measured at time 1 and time 2), the risk for coronary heart disease in men with high-tertile triglyceride levels at time 1 changed depending on the tertile at time 2 (hazard ratios, 8.23 [95\% CI, 2.50 to 27.13] for high/high, 6.84 [CI, 1.95 to 23.98] for high/intermediate, and 4.90 [CI, 1.01 to 24.55] for high/low, compared with the stable low/low group). The risk in men with low-tertile levels at time 1 also changed depending on the tertile at time 2 (hazard ratios, 3.81 [CI, 0.96 to 15.31 ] for low/intermediate and 6.76 [CI, 1.34 to 33.92] for low/high, compared with the stable low/low group). On the contrary, a decrease in initially elevated triglyceride levels was associated with a decreased risk compared with stable high triglyceride levels. However, still this risk remained higher than in those with persistently low triglyceride levels. Therefore, there is strong epidemiological evidence for the association between fasting and even more for nonfasting triglycerides and cardiovascular disease. The robustness of this association depends on design of the study and statistical standardization.

\section{Most frequently encountered discussed disorders associated hypertriglyceridemia}

and with

Moderately elevated plasma/serum triglycerides signalize increased risk for cardiovascular disease, extremely elevated triglycerides signalize increased risk for pancreatitis and lipemia retinalis. Several genetic and non-genetic factors are included in regulation of triglycerides levels. Extremely elevated triglycerides (concentration more than $10 \mathrm{mmol} / \mathrm{l}$ ) not provoked by dietary factors, especially by high alcohol intake are more likely to have a monogenic cause. On the contrary, mildly to moderately elevated triglycerides (concentration 2 to $10 \mathrm{mmol} / \mathrm{l}$ ) have mostly polygenic origin and often coexist with other metabolic disturbances, mainly with central obesity, insulin resistance and diabetes mellitus.
However, changes of circulating triglycerides are rather marker for changes in several metabolic pathways, some of them definitely associated with so called cardiometabolic risk. Most recently discussed is the role of Apo C-III which inhibits triglyceride hydrolysis and has been implicated in coronary artery disease (Boren et al. 2015, Wyller von Ballmoos et al. 2015).

In particular, the increase in circulating triglycerides could signalize several entities and is associated with several diseases. The most frequently discussed ones are listed bellow and in Table 2.

From the point of view of atherosclerosis and cardiovascular disease there are three main areas where increased triglycerides indirectly indicate increased risk. First, increased triglycerides in fasting and even more in nonfasting status could be marker for increased levels of remnant lipoprotein particles, which could be directly atherogenic, they could penetrate into the vessel wall and cause inflammation. In contrast to LDL particles, they do not need to be modified/oxidized to become atherogenic (Varbo et al. 2014). They could be more important in women (McNamara et al. 2001) especially in women changing reproductive status from premenopause to menopause (Pitha et al. 2015). Their reliable measurement was based on sophisticated and not widely available methods (Nakajima et al. 1996, Nakano et al. 2011). Recent studies used so called nonHDL/nonLDL cholesterol obtained mainly from nonfasting blood and calculated as total cholesterol minus LDL cholesterol minus HDL cholesterol. This parameter could rather reliably reflect cholesterol content in remnant lipoprotein particles and is strongly associated with cardiovascular events (Varbo et al. 2014).

Second and already mentioned is the inappropriate impact of Apo C-III on metabolism of lipids, which often leads to hypertriglyceridemia. Recent study focused on factors that predict the kinetics of VLDL1 triglycerides in 50 subjects with abdominal obesity and additional cardiometabolic risk factors. It showed that plasma triglyceride concentrations were dependent on both the secretion rate and fractional catabolism of VLDL1-triglycerides and VLDL1-apoB. Liver fat mass was independently and directly associated with secretion rates of VLDL1-triglycerides and VLDL1apoB. Also plasma Apo C-III concentration was independently and inversely associated with the fractional catabolisms of VLDL1-triglycerides and VLDL1-apoB. These results indicated that plasma triglyceride concentrations in abdominal obesity were determined by 
the kinetics of VLDL1 subspecies, catabolism being mainly dependent on Apo C-III concentration and secretion on liver fat content. Therefore, reduction in liver fat and targeting Apo C-III may be an effective approach for correcting triglyceride metabolism atherogenic dyslipidemia in obesity (Boren et al. 2015). The atherogenic process in general could be described in general as follows. Triglyceride-rich lipoprotein metabolism shifts from an apolipoprotein E system in normotriglyceridemic participants characterized by rapid clearance from circulation of very low density lipoproteins to an Apo C-III system in hypertriglyceridemic subjects, which is characterized by reduced clearance of triglyceride-rich lipoproteins and the formation of increased number the dense LDL particles more prone to modification/oxidation and therefore more atherogenic (Stavek et al. 1998, Sacks 2015).

Third, increased triglycerides could also indicate malfunctioning reverse cholesterol transport, namely malfunctioning of fraction cholesterol esterification rate of HDL as a causative factor of increased cardiovascular risk. The fraction esterification rate could be measured by rather sophisticated laboratory methods, but can be also reliably assessed by simple calculation from standard lipid profile as a logarithmically transformed ratio of molar concentrations of triglycerides to HDL-cholesterol. This parameter was named atherogenic index of plasma (AIP) (Dobiasova et al. 2006, Frohlich et al. 2001). The close association of fraction esterification rate of HDL with AIP can be explained by triglyceride participation in the production of large VLDL and small dense LDLs and have also been proposed to be the major determinants of cholesterol esterification/transfer and HDL remodeling in particles that regulate the esterification rate. The strong correlation of AIP with HDL lipoprotein particle size may also explain its high predictive value. It was proved, that AIP values significantly increase with increasing cardiovascular risk. Based on data from young children, healthy women, men and subjects with hypertension, diabetes mellitus, and mainly hypetriglyceridemia it was suggested that AIP values of -0.3 to 0.1 are associated with low, 0.1 to 0.24 with medium and above 0.24 with high cardiovascular risk. In the population study men had higher AIP values than women. In patients undergoing coronary angiography, in statistical model that included age, body mass index, waist circumference, diabetes mellitus type 2, blood pressure, smoking, triglycerides, total, LDL, HDL cholesterol, ratio of total to HDL cholesterol and apolipoprotein B, AIP was the best predictor of positive findings (Dobiasova et al. 2011). AIP was also a highly sensitive marker of differences in lipoprotein profiles in families of patients with premature myocardial infarction and in control families. As a marker of lipoprotein particle size it adds predictive value beyond that of the individual lipids including total/HDL cholesterol ratio. However, the changes of these risk biomarkers with different therapies and their relation to treatment outcomes have not been studied.

Another recently discussed entity is microvascular disease in patients with diabetes mellitus type 2 and its reduction by treatment by fenofibrate, drug reducing triglycerides (Rajamani et al. 2009). The mechamism is not clear but according to studies of renal diseases in diabetes mellitus it seems possible that causative factor might be stimulation of transforming growth factor beta by triglyceride-rich lipoproteins and inducing the production of reactive oxygen species causing damage to the glomeruli and glomerular glycocalyx and it could be speculated that these processes could also affect basal membranes in small vessels not only in kidneys. This hypothesis is supported by findings from experimental and clinical studies which strongly suggest that excess amounts of a triglyceride-rich lipoproteins worsens diabetes-associated microvascular and macrovascular disease, increases glomerular injury, increases tubulointerstitial fibrosis, and accelerates the progression of diabetic nephropathy (Rutledge et al. 2010).

Frequently discussed disorder associated with hypertiglyceridemia is non-alcoholic steatohepatitis. Liver inadequate triglyceride accumulation is probably one of the most frequent pathology in industrialized populations caused by an excess of energy intake for prevailing energy expenditure and/or higher alcohol intake and is probably also influenced by composition of diet, when high intake of saturated fatty acids or fructose could play an additional role (Jacome-Sosa 2014, Zimmermann et al. 2009). Therefore, reduction in liver fat and targeting of already discussed Apo C-III may be an effective approach for correcting triglyceride metabolism atherogenic dyslipidemia in obesity (Boren et al. 2015).

Extreme hypertriglyceridemia could be also strong risk factors of pancreatitis. The mechanisms are still not well understood but there is still permanently discussed hypothesis initially raised by Havel (1969) which focuses on the excess of triglycerides hydrolyzed by high levels of pancreatic lipase released in the vascular 
bed of the pancreas. Subsequently, free fatty acids are formed in high concentrations, which overwhelm the binding capacity of albumin and they self-aggregate to micellar structures with detergent properties and then acinar cell and pancreatic capillary injury is promoted. The resultant ischemia creates an acidic environment, which further triggers free fatty acids toxicity.
Additionally, the elevated levels of chylomicrons increase the viscosity of blood and therefore impair the blood flow in the pancreas causing ischemia and acidosis within the pancreas. Furthermore, endoplasmic reticulum stress is also discussed as a causative factor (Havel 1969, Valdivielso et al. 2014).

Table 2. Role of elevated triglycerides in cardiovascular and other diseases.

\begin{tabular}{|c|c|c|c|}
\hline & Triglycerides signalize & Mechanism(s) & Detected by \\
\hline \multirow[t]{4}{*}{$\begin{array}{l}\text { Cardiovascular } \\
\text { disease }\end{array}$} & $\begin{array}{l}\text { Elevated remnant } \\
\text { lipoproteins }\end{array}$ & $\begin{array}{l}\text { Direct atherogenic effect } \\
\text { (inflammation of the vessel } \\
\text { wall) }\end{array}$ & $\begin{array}{l}\text { Non-HDL cholesterol } \\
\text { Non-HDL/non-LDL } \\
\text { cholesterol (nonfasting) }\end{array}$ \\
\hline & $\begin{array}{l}\text { Presence of increased } \\
\text { number of small LDL } \\
\text { particles }\end{array}$ & $\begin{array}{l}\text { Proatherogenic effect } \\
\text { (increased modification/ } \\
\text { oxidation of LDL) }\end{array}$ & Apolipoprotein B \\
\hline & $\begin{array}{l}\text { Impaired reverse cholesterol } \\
\text { transport }\end{array}$ & $\begin{array}{l}\text { Impaired esterification rate } \\
\text { of HDL cholesterol }\end{array}$ & $\begin{array}{l}\text { Low HDL cholesterol, } \\
\text { Decreased level of } \\
\text { apolipoprotein AI, Increased } \\
\text { atherogenic index of plasma } \\
(\log (\operatorname{tg} / \mathrm{HDL}))\end{array}$ \\
\hline & $\begin{array}{l}\text { Increased level of } \\
\text { apolipoprotein C-III }\end{array}$ & $\begin{array}{l}\text { Lipoprotein lipase activity } \\
\text { inhibited by apolipoprotein } \\
\text { C-III }\end{array}$ & Hypertriglyceridemia \\
\hline Microvascular disease & $\begin{array}{l}\text { Not well controlled diabetes } \\
\text { mellitus }\end{array}$ & $\begin{array}{l}\text { Activation of transforming } \\
\text { growth factor beta by } \\
\text { triglyceride-rich lipoproteins }\end{array}$ & $\begin{array}{l}\text { Hypertriglyceridemia } \\
\text { Clinical findings }\end{array}$ \\
\hline Pancreatitis & Increased FFA in circulation & $\begin{array}{l}\text { Not exatly known, might be } \\
\text { activation of pancreatic } \\
\text { enzymes by increased FFA }\end{array}$ & $\begin{array}{l}\text { Clinical findings: elevated } \\
\text { urine amylases }\end{array}$ \\
\hline Steatohepatitis & $\begin{array}{l}\text { Triglycerides marker of } \\
\text { impaired lipoprotein } \\
\text { transport from liver }\end{array}$ & $\begin{array}{l}\text { Liver inadequate } \\
\text { triglyceride accumulation }\end{array}$ & $\begin{array}{l}\text { Moderate } \\
\text { hypertriglyceridemia and } \\
\text { elevated liver tests and often } \\
\text { C-reactive protein }\end{array}$ \\
\hline Lipemia retinalis & $\begin{array}{l}\text { Triglyceride rich particles - } \\
\text { chylomicrons in substantially } \\
\text { increased concentration }\end{array}$ & $\begin{array}{l}\text { Dispersion of light caused by } \\
\text { chylomicrons }\end{array}$ & $\begin{array}{l}\text { Imaging of optic fundi } \\
\text { Extreme } \\
\text { hypertriglyceridemia }\end{array}$ \\
\hline
\end{tabular}

* FFA - free fatty acids.

Rather rare consequence of hypertriglyceridemia is lipemia retinalis which is a rare and asymptomatic condition which occurs when high levels of triglycerides and chylomicrons are present in blood. Creamy white appearance of retinal vessels occurs when triglyceride value reaches more than 20-30 mmol/l. Fundus changes are probably caused by dispersion of light caused by chylomicrons, which are presented in substantially increased numbers/concentrations. These findings most commonly occur in familial hyperchylomicronemia, an autosomal recessive disorder associated with lipoprotein lipase or apolipoprotein C-II deficiency (Fred and Accad 1999). 


\section{Assessment of atherogenicity associated with triglycerides in clinical practice}

The main task in clinical practice is to assess if hypertriglyceridemia is atherogenic. Several simple rules could help in such assessment. First, mild hypertriglyceridemia is most frequently associated with increased cardiovascular risk. If hypertriglyceridemia is more than 5-10 mmol/l its atherogenic potential could be decreased. In mild hypertriglyceridemia, non-HDL cholesterol (total minus HDL cholesterol) and/or apolipoprotein B could be reliable markers of atherogenic lipid profile as shown in Table 3 (Vaverkova et al. 2007). Recently, as already mentioned, simple method is used for assessment of cholesterol content of remnant lipoprotein particles by formula: total cholesterol minus LDL cholesterol minus HDL cholesterol (Varbo et al. 2014). However, in this case no recommended/target values are available and future studies are needed. The status of reverse cholesterol transport potentially affected by hypetriglyceridemia could be assessed by atherogenic index of plasma, where safe values are approximately 0 and less (Dobiasova et al. 2011).

Table 3. Target values of atherogenic plasma lipids in patients at very high risk (Vaverkova et al. 2007).

$\begin{array}{ll}\text { LDL-cholesterol } & \text { Lower than } 2.0 \mathrm{mmol} / 1 \\ \text { Non-HDL-cholesterol } & \text { Lower than } 2.8 \mathrm{mmol} / 1^{*} \\ \text { Apolipoprotein B } & \text { Lower than } 0.8 \mathrm{~g} / 1^{*}\end{array}$

* recommended if the concentration of triglycerides exceeds $2.3 \mathrm{mmol} / \mathrm{l}$.

\section{References}

AUSTIN MA: Epidemiology of hypertriglyceridemia and cardiovascular disease. Am J Cardiol 83: 13F-16F, 1999.

BANSAL S, BURING JE, RIFAI N, MORA S, SACKS FM, RIDKER PM: Fasting compared with nonfasting triglycerides and risk of cardiovascular events in women. JAMA 298: 1309-1316, 2007.

BORÉN J, WATTS GF, ADIELS M, SÖDERLUND S, CHAN DC, HAKKARAINEN A, LUNDBOM N, MATIKAINEN N, KAHRI J, VERGÈS B, BARRETT PH, TASKINEN MR: Kinetic and related determinants of plasma triglyceride concentration in abdominal obesity: multicenter tracer kinetic study. Arterioscler Thromb Vasc Biol 35: 2218-2224, 2015.

DOBIÁSOVÁ M: AIP - atherogenic index of plasma as a significant predictor of cardiovascular risk: from research to practice (in Czech). Vnitr Lek 52: 64-71, 2006.

DOBIÁSOVÁ M, FROHLICH J, SEDOVÁ M, CHEUNG MC, BROWN BG: Cholesterol esterification and atherogenic index of plasma correlate with lipoprotein size and findings on coronary angiography. $J$ Lipid Res 52: 566-571, 2011.

FRED HL, ACCAD M: Lipemia retinalis. N Eng J Med 340: 1969, 1999. 
FROHLICH J, DOBIASOVA M, LEAR S, LEE KW: The role of risk factors in the development of atherosclerosis. Crit Rev Clin Lab Sci 38: 401-440, 2001.

HAVEL RJ: Pathogenesis, differentiation and management of hypertriglyceridemia. Adv Intern Med 15: 117-154, 1969. HAVEL RJ: Postprandial hyperlipidemia and remnant lipoproteins. Curr Opin Lipidol 5: 102-109, 1994.

HEGELE RA, GINSBERG HN, CHAPMAN MJ, NORDESTGAARD BG, KUIVENHOVEN JA, AVERNA M, BORÉN J, BRUCKERT E, CATAPANO AL, DESCAMPS OS, HOVINGH GK, HUMPHRIES SE, KOVANEN PT, MASANA L, PAJUKANTA P, PARHOFER KG, RAAL FJ, RAY KK, SANTOS RD, STALENHOEF AF, STROES E, TASKINEN MR, TYBJÆRG-HANSEN A, WATTS GF, WIKLUND O; EUROPEAN ATHEROSCLEROSIS SOCIETY CONSENSUS PANEL: Lancet Diabetes Endocrinol 2: 655-666, 2014.

HOKANSON JE, AUSTIN MA: Plasma triglyceride level is a risk factor for cardiovascular disease independent of high-density lipoprotein cholesterol level: a metaanalysis of population-based prospective studies. J Cardiovasc Risk 3: 213-219, 1996.

JACOME-SOSA MM, PARKS EJ: Fatty acid sources and their fluxes as they contribute to plasma triglyceride concentrations and fatty liver in humans. Curr Opin Lipidol 25: 213-220, 2014.

KOVAR J, ZEMANKOVA K: Moderate alcohol consumption and triglyceridemia. Physiol Res 64 (Suppl 3): S371S375, 2015.

LIBBY P: Triglycerides on the rise: should we swap seats on the seesaw? Eur Heart J 36: 774-776, 2015.

MCNAMARA JR, SHAH PK, NAKAJIMA K, CUPPLES LA, WILSON PW, ORDOVAS JM, SCHAEFER EJ: Remnant-like (RLP) cholesterol is an independent cardiovascular risk factor in women: results from the Framingham Heart Study. Atherosclerosis 154: 229-236, 2001.

NAKAJIMA K, OKAZAKI M, TANAKA A, PULLINGER CR, WANG T, NAKANO T, ADACHI M, HAVEL RJ: Separation and determination of remnant-like particles in human serum using monoclonal antibodies to Apo B-100 and Apo A-1. J Clin Ligand Assay 19: 177-183, 1996.

NAKANO T, TOKITA Y, NAGAMINE T, TANAKA A, OKAZAKI M, YATSUZUKA S, TAMEI N, SHIMOMURA Y, ANDO Y, AKAMATSU S, FUJITA MQ, NAKAJIMA K: Measurement of serum remnant-like lipoprotein particle-triglyceride (RLP-TG) and RLP-TG/total TG ratio using highly sensitive triglyceride assay reagent. Clin Chim Acta 412: 71-78, 2011.

NORDESTGAARD BG, BENN M, SCHNOHR P, TYBJAERG-HANSEN A: Nonfasting triglycerides and risk of myocardial infarction, ischemic heart disease, and death in men and women. JAMA 298: 299-308, 2007.

NORDESTGAARD BG, VARBO A: Triglycerides and cardiovascular disease. Lancet 384: 626-635, 2014.

PATEL A, BARZI F, JAMROZIK K, LAM TH, UESHIMA H, WHITLOCK G, WOODWARD M; ASIA PACIFIC COHORT STUDIES COLLABORATION: Serum triglycerides as a risk factor for cardiovascular diseases in the Asia-Pacific region. Circulation 110: 2678-2686, 2004.

PIŤHA J, KOVÁŘ J, ŠKODOVÁ Z, CÍFKOVÁ R, STÁVEK P, ČERVENKA L, ŠEJDA T, LÁNSKÁ V, POLEDNE $\mathrm{R}$ : Association of intima-media thickness of carotid arteries with remnant lipoproteins in men and women. Physiol Res 64 (Suppl 3): S377-S384, 2015.

POLLIN TI, DAMCOTT CM, SHEN H, OTT SH, SHELTON J, HORENSTEIN RB, POST W, MCLENITHAN JC, BIELAK LF, PEYSER PA, MITCHELL BD, MILLER M, O'CONNELL JR, SHULDINER AR: A null mutation in human APOC3 confers a favorable plasma lipid profile and apparent cardioprotection. Science 322: 1702-1705, 2008.

RAJAMANI K, COLMAN PG, LI LP, BEST JD, VOYSEY M, D'EMDEN MC, LAAKSO M, BAKER JR, KEECH AC; FIELD STUDY INVESTIGATORS: Effect of fenofibrate on amputation events in people with type 2 diabetes mellitus (FIELD study): a prespecified analysis of a randomised controlled trial. Lancet 373: 1780$1788,2009$.

RUTLEDGE JC, NG KF, AUNG HH, WILSON DW: Role of triglyceride-rich lipoproteins in diabetic nephropathy. Nat Rev Nephrol 6: 361-370, 2010.

SACKS FM: The crucial roles of apolipoproteins E and C-III in apoB lipoprotein metabolism in normolipidemia and hypertriglyceridemia. Curr Opin Lipidol 26: 56-63, 2015. 
STÁVEK P, PIŤHA J, POLEDNE R: Small, density lipoprotein particles - methods and risk in Czech population (in Czech). Klin Biochem Metab 27: 68-71, 1998.

THOMSEN M, VARBO A, TYBJÆRG-HANSEN A, NORDESTGAARD BG: Low nonfasting triglycerides and reduced all-cause mortality: a mendelian randomization study. Clin Chem 60: 737-746, 2014.

TIROSH A, RUDICH A, SHOCHAT T, TEKES-MANOVA D, ISRAELI E, HENKIN Y, KOCHBA I, SHAI I: Changes in triglyceride levels and risk for coronary heart disease in young men. Ann Intern Med 18: 377-385, 2007.

VALDIVIELSO P, RAMÍREZ-BOLLERO J, PÉREZ-LÓPEZ C: Peripheral arterial disease, type 2 diabetes and postprandial lipidaemia: Is there a link? World J Diabetes 5: 577-585, 2014a.

VALDIVIELSO P, RAMÍREZ-BUENO A, EWALD N: Current knowledge of hypertriglyceridemic pancreatitis. Eur $J$ Intern Med 25: 689-694, 2014b.

VARBO A, NORDESTGAARD BG: Remnant cholesterol and ischemic heart disease. Curr Opin Lipidol 25: 266-273, 2014.

VAVERKOVÁ H, SOSKA V, ROSOLOVÁ H, CESKA R, CÍFKOVÁ R, FREIBERGER T, PIT'HA J, POLEDNE R, STULC T, URBANOVÁ Z, VRÁBLÍK M, CZECH ATHEROSCLEROSIS SOCIETY: Czech atherosclerosis society guidelines for the diagnosis and treatment of dyslipidemia in adults (in Czech). Cas Lek Cesk 146: II-XV, 2007.

VRABLIK M, CESKA R: Treatment of hypertriglyceridemia: a review of current options. Physiol Res 64 (Suppl 3): S331-S340, 2015.

WHITE BA: Hormonal regulation of energy metabolism. In: Berne and Levy Physiology ( $6^{\text {th }}$ edition). KOEPPEN BM, STANTON BA (eds), Mosby Elsevier, Philadelphia, 2010, pp 668-675.

WYLER VON BALLMOOS MC, HARING B, SACKS FM: The risk of cardiovascular events with increased apolipoprotein CIII: A systematic review and meta-analysis. J Clin Lipidol 9: 498-510, 2015.

ZIMMERMAN R, LASS A, HAEMERLE G, ZECHNER R: Fate of fat: the role of adipose triglyceride lipase in lipolysis. Biochim Biophys Acta 1791: 464-500, 2009. 